Published in final edited form as:

Can J Chem. 2017 September ; 95(9): 897-902. doi:10.1139/cjc-2017-0193.

\title{
Dendrimers for Ocular Drug Delivery
}

\author{
Michael G. Lancina III ${ }^{1}$ and Hu Yang ${ }^{2,3,4,}{ }^{*}$ \\ ${ }^{1}$ Department of Biomedical Engineering, Virginia Commonwealth University, Richmond, VA \\ 23284, United States \\ ${ }^{2}$ Department of Chemical \& Life Science Engineering, Virginia Commonwealth University, \\ Richmond, VA 23219, United States \\ ${ }^{3}$ Department of Pharmaceutics, Virginia Commonwealth University, Richmond, VA 23298, United \\ States \\ ${ }^{4}$ Massey Cancer Center, Virginia Commonwealth University, Richmond, VA 23298, United States
}

\begin{abstract}
Existing methods of administering ocular drugs are limited in either their safety or efficiency. Nanomedicine therapies have the potential to address this deficiency by creating vehicles that can control drug biodistribution. Dendrimers are synthetic polymeric nanoparticles with a unique highly organized branching structure. In recent years, promising results using dendrimer vehicles to deliver ocular drugs through different routes of administration have been reported. In this review, we briefly summarize these results with emphasis on the dendrimer modifications used to target different ocular structures.
\end{abstract}

\section{Keywords}

dendrimer; ocular drug delivery; nanomedicine

\section{Introduction}

Delivery of therapeutic compounds to the eye remains one of the largest unmet needs in advanced drug delivery research. The massive market for ocular drugs, and the deficiencies of current delivery methods create a tremendous opportunity for developing novel materials to improve patient outcomes and reduce costs. ${ }^{1-3}$ Existing treatments are generally inadequate because both the structure and the function of the eye create significant hurdles to delivering therapeutic compounds safely and efficiently. Delivery through systemic circulation would be the simplest method for patients to self-administer, but drug transport to most ocular structures is very low or isolated by specialized selective barriers. ${ }^{4}$ Topical delivery is straightforward and safe, but the combined effects of low corneal permeability and washout by tear fluid make this route highly inefficient as well. ${ }^{5}$ More invasive approaches such as direct intravitreal or periocular injections are efficient, but unattractive

*Correspondence should be addressed to Hu Yang, Department of Chemical and Life Science Engineering, Virginia Commonwealth University, 737 North $5^{\text {th }}$ Street, Biotech 8, Richmond, VA 23219, United States. Tel: (804) 828-5459; hyang2@vcu.edu. 
from a safety and cost perspective. Finally, poor solubility and systemic side effects are problems with many ocular drugs independent of route of administration. ${ }^{6}$

Despite the clear need for improved vehicles, an ideal solution has yet to be developed. Nanoparticle-based drug delivery systems have been theorized and investigated for decades, but only recent years have seen rapid growth in the application of these systems. ${ }^{7,8}$ Nanoparticles fabricated from a wide range of materials including polymers (natural and synthetic), liposomes, and polysaccharides have shown enhanced delivery of ocular therapeutics. ${ }^{9-12}$ Alternative strategies such as in-situ polymerizing hydrogels and erodible inserts have been developed. ${ }^{13-16}$ The biodistribuition of these nanomaterials in ocular tissues allows them to serve as vehicles that compared to simple drug solutions: 1) increase quantity of drug that reaches the target organ, 2) increase the length of time the drug remains at the target organ, 3 ) reduce the quantity of drug in off-target tissues. ${ }^{17}$

One class of polymers that has shown particular promise in ocular applications are dendrimers. ${ }^{18,19}$ These uniquely structured polymeric nanoparticles provide versatile platforms capable of delivering the complete array of ocular therapeutics ${ }^{20}$. Dendrimer science is still in its infancy, with the first synthetic molecules being synthesized in the mid $1980 \mathrm{~s}^{21}$. Still, by this point some level of study has been conducted using dendrimers with all available routes of ocular administration (Fig 1). This review briefly discusses the key considerations when designing dendrimers for ocular drug delivery as well as recent developments in the field. It also briefly outlines possible future directions for dendrimerbased materials and the possible regulatory hurdles that need to overcome.

\section{Anatomy and Physiology of the Eye}

Both the underlying structure and ongoing physiologic processes in the eye create major barriers to ocular drug delivery. ${ }^{22}$ The eye is divided into two major chambers-the anterior and posterior segments. The anterior segment of the eye contains everything between the lens and the cornea and is filled with a continuously circulating aqueous fluid. The posterior segment of the eye is the portion between the lens and the choroid and it is filled with a more gelatinous fluid called the vitreous humor. Anterior segment diseases such as corneal wounds, glaucoma, and conjunctivitis are generally targeted with topical eye drops. ${ }^{23}$ Posterior segment diseases such as macular degeneration and retinopathy cannot currently be treated with topical vehicles and require more invasive techniques such as direct injections or surgical interventions. ${ }^{24,25}$

\section{Routes of Administration}

\section{Topical delivery}

Topical delivery of ocular drugs, virtually always in the form of saline eye drops applied directly to the cornea, has the advantage of being the simplest route of administration. For drugs directed at anterior segment diseases, such as intra-ocular pressure lowering agents, these drops are a safe and cost-effective treatment option. However, these therapies suffer from notoriously poor patient compliance due ultimately to the poor delivery efficiency of eye drops. ${ }^{26-28}$ Even under ideal conditions, only around $5 \%$ of the drug placed on the eye 
reaches the anterior chamber. ${ }^{29}$ Permeation though the tightly packed epithelium of the cornea and sclera is slow for anything but the smallest, most lipophilic compounds. ${ }^{30}$ At the same time, tear turnover is relatively rapid, with virtually all of the eye drop drained from the ocular surface within 15 minutes after instillation. ${ }^{23}$ To counter poor delivery efficiency, eye drops must either utilize higher drug concentrations or a more frequent dosing schedule. Both are burdensome on patients in the form of even greater quantities of the drug in offtarget tissues, often resulting in side effects. Successful topical ocular drug delivery vehicles must then either increase the permeation rate of their material across the cornea or prolong the residence time of the drug on the ocular surface. ${ }^{14,31,32}$

\section{Systemic administration}

Systemic administration is not commonly used with ocular drug therapies. Although it would solve some of the patient compliance problems of topical delivery while remaining simple and inexpensive, efficiencies are even lower. In the anterior segment, blood perfusion rate is incredibly low, even relative to the size of the tissue. The posterior segment does have significant vascularization, but almost all of it is concentrated in the choroid and separated from direct access to the retina by the blood-retina-barrier. ${ }^{33}$ While some compounds can be delivered to the eye through systemic administration, the concentrations needed to achieve therapeutic efficacy often result in many of the same side effects observed with topical administration.

\section{Injections}

The only highly efficient route of administering ocular drugs currently in practice are intravitreal and periocular injections. Both of these methods deliver high doses of drug in a tightly targeted manner, but they come with significant drawbacks. Intravitreal injections are the most direct possible route to deliver drugs to the interior ocular structures, but they also carry the greatest risk of damage to the eye because the needle tip is hidden during the procedure. ${ }^{34,35}$ Injections into the surrounding structures such as the periocular tendons minimize most of these risks, but they are still highly invasive and expensive. ${ }^{36}$ Critically, these methods are not viable for managing chronic diseases like glaucoma. Serious risk factors associated with an individual injection are slight, but their chance of occurring rises greatly when injections are used repeatedly and frequently. Strategies to improve ocular drug delivery injections focus mainly on building extended release mechanisms that can act as long term drug reservoirs in situ and minimize the necessary dosing regimen.

\section{Dendrimers}

The term 'dendrimer' refers to any polymer composed of repeating, regularly branching units. A large number of chemically distinct dendrimer families have been synthesized, but very few have been studied in depth. Only one, polyamidoamine (PAMAM) dendrimers have been commercialized. ${ }^{21}$ The synthesis of PAMAM dendrimers begins with a central core molecule and 'generations' of branches are added in a series of sequential reactions (Fig 2). This reaction scheme produces highly monodisperse, spherical nanoparticles. With each successive generation, the radius of the particle increases linearly, while the number of terminal groups and molecular weight grow exponentially. 
This unique structure gives dendrimers a number of useful properties for drug delivery not shared by linear polymers. ${ }^{37}$ Primarily, their well-defined core-shell architecture and narrow polydispersity make bio-distribution more predictable and easier to control through modifications to the terminal groups. ${ }^{38}$ Also, drugs and other therapeutics can be loaded onto the nanoparticle through multiple modalities, such as direct conjugation, ionic interactions, or trapping in the core of the particle. ${ }^{39}$ This versatility makes dendrimers highly adaptable platforms that can be designed to carry a wide range of therapeutics to a wide range of targets. ${ }^{40}$ In ocular drug delivery research groups have utilized this versatility to develop dendrimer based strategies for multiple routes of administration (Table 1). While this review is focused primarily on PAMAM dendrimers because they are the closest to clinical translation, it is important to recognize the growing body of research on alternative dendrimer particles in ocular drug delivery. These include phosphorous, carbosilane, and peptide based dendritic nanoparticles. ${ }^{41-44}$ As the science matures, these novel structures may represent the future of dendrimer nanoparticle drug delivery vehicles.

\section{Topical Formulations}

Topical application, being the most direct and simplest method of ocular drug delivery, was the first route investigated with dendrimer-based vehicles. ${ }^{45}$ Cationic nanoparticles have shown efficacy as permeation enhancers for transepithelial drug delivery. ${ }^{46-48}$ PAMAM dendrimers are strongly cationic on the full generations when amine terminated (G3.0, G4.0, G5.0, etc.), so logically they should increase corneal permeability when applied in aqueous solution. Vandamme et al. undertook systematic studies on the corneal residence time of PAMAM dendrimers with an in vivo rabbit model. ${ }^{49}$ They found residence time was highly dependent on the generation and terminal groups on the particle. In general, larger and hydroxyl terminated dendrimers showed increased corneal residence time and drug delivery efficacy in these tests. The authors hypothesized this effect was dominated by the dendrimers interaction with ocular muscins, which impede washout of the drug. EX vivo corneal permeation experiments by Yao et al. several years later also found improved drug delivery efficacy with increasing dendrimer generation, but they attributed this instead to greater disruption of corneal epithelial tight junctions by the larger (and more cationic) particles. ${ }^{50}$ Likely, both phenomena are at work and represent important aspects of dendrimer based ocular drug delivery. ${ }^{51-53}$

A similar but distinct strategy for utilizing topically applied dendrimers is to incorporate them into in situ polymerizing gels. This approach relies on the same principle that prolonging corneal residence time can improve drug delivery efficiency, given most drops are rapidly drained from the ocular surface. Dendrimers are highly versatile gel forming agents (Fig. 3). ${ }^{54}$ There are several potential strategies for fabricating mucoadhesive ocular hydrogels from PAMAM dendrimers alone. ${ }^{55-57}$ The properties of these materials can be easily tuned by modifying parameters such as the concentration of polymer in solution or the number of reactive groups present. This is critical to controlling the drug release kinetics and total residence time of the gel. Photocurable dendrimer-poly(lactic-co-glycolic) acid hydrogels were first developed and tested in 2012 by Holden et al. ${ }^{58}$ During UV initiated polymerization, the loose network trapped nanoparticles containing anti-glaucoma drugs, and slowly released them over a four day period. Because the gel network was completely 
independent of the drug nanoparticles, this material could easily be adapted to deliver different ocular therapeutics.

\section{Injectable Formulations}

Intravitreal injection has become an increasingly common method of ocular drug delivery over the last 15 years. ${ }^{59}$ Several physiochemical properties of PAMAM dendrimers can be modified to give them a very long residence time in the vitreous cavity. Dendrimers of varying generations and drug conjugations have been studied utilizing this route by several groups. ${ }^{60-62}$ Kambhampati et al. injected G4 PAMAM dendrimers conjugated with an antiinflammatory drug and showed the conjugates selectively migrated to cells in the retinal pigmented epithelium and activated microglial cells. ${ }^{63}$ These conjugates took advantage of phagocytosis by activated inflammatory cells to prolong nanoparticle residence time, but in theory other dendrimer properties could be used to develop long term vitreal drug reservoirs. $E_{X}$ vivo modeling studies have shown diffusion through the vitreous humor for nanoparticles the size of dendrimers $(<10 \mathrm{~nm})$ is dependent entirely on the surface charge of the particle. ${ }^{64-66}$ Highly cationic dendrimers should associate strongly with the anionic glycans of the vitreous humor, but the cytotoxicity of these particles needs to be reduced with a passivating polymer such as poly(ethylene glycol). ${ }^{67}$

Periocular injections offer many of the same potential benefits as intravitreal injections in terms of highly efficient extended drug delivery, but with a less delicate injection site. To date studies on periocular dendrimer injections have focused on subconjunctival delivery. This delivery site protects the nanoparticles from washout by tear drainage, but still requires trans-scleral permeation. ${ }^{68}$ Dendrimers in this application can be used to solubilize hydrophobic drugs and provide a sustained release depot adjacent to the sclera. ${ }^{68-70}$ Sustained delivery vehicles have many advantages from a patient compliance standpoint, but they can also make existing therapeutics more effective. Kang et al. used PAMAM based aggregates to deliver the chemotherapeutic carboplatin over a three-week period following a single subconjunctival injection. ${ }^{71}$ The presence of the dendrimer network dramatically reduced the toxicity of the drug, allowing for the use of an increased therapeutic concentration and corresponding reduction in tumor volume.

Dexamethasone (DEX) is a particularly important ocular therapeutic with limited bioavailability. ${ }^{72,73}$ While this glucocorticoid has been shown to effectively reduce inflammation following eye injury, it is also rapidly cleared from both chambers. ${ }^{15}$ Recent studies by Yavuz et al. and Soiberman et al. have utilized hydroxyl terminated PAMAM dendrimers to sustain DEX delivery after subconjunctival injection. ${ }^{69,74}$ In the former, DEX delivery was directed toward the posterior segment. In the latter, corneal inflammation was the target. Both studies showed increased DEX delivery efficiency and longer residence time compared to simple solution injection. These two studies highlight the potential of dendrimer based injection systems as promising strategies to treat both anterior and posterior segment diseases. 


\section{Conclusions \& Future Directions}

Even with a growing body of promising research, commercialization of dendrimer based drug delivery systems remains slow. Dendrimers exist in a unique space where they are much larger than traditional small molecule drugs and much smaller than traditional polymeric particles but have biological properties similar to both. This has created a number of barriers to clinical approval that industry and the regulatory agencies have yet to work out. ${ }^{75}$ First, the long-term safety of dendrimers is a primary concern. ${ }^{76}$ Dendrimers are small enough (in most formulations) that they will ultimately end up entering systemic circulation regardless of their initial route of administration. ${ }^{4,77}$ This makes overall safety an incredibly complicated area of study because the local biodistribuition, toxicity, and complete biological activity of the vehicle must be determined in many different tissues at many different time points. ${ }^{78}$ Even for unmodified PAMAM dendrimers, there is a tremendous amount of work left to be completed. When you consider that a principle advantage of dendrimers is how easy they are to modify with additional groups to control biodistribuition, it is not surprising that creation of novel conjugates has outpaced deep study of their systemic safety. The reliability and purity of commercial sources (or lack thereof), is another bottleneck. Scale up for production and purification of complex conjugates is going to require novel processes that are usually outside of the purview of the labs developing these technologies. ${ }^{79}$ There are also purely bureaucratic questions that remain unresolved. Chiefly, are dendrimer-drug conjugates considered novel drugs or medical devices by the FDA? It would appear that most dendrimer vehicles would classify as combination devices, but even in such cases the lead center of the FDA is not clear. It seems these questions may continue until one PAMAM based vehicle breaks through to clinical approval and establishes precedent. Regulatory approval has been swifter in Europe, where OcuSeal ${ }^{\mathrm{TM}}$, a dendrimer based cornea sealant was approved for human use in 2009.

Despite these challenges, it is clear from recent research that dendrimers hold tremendous potential as ocular drug delivery vehicles. Research groups around the world have been able to develop dendrimer based materials which have shown improved drug delivery efficacy when applied directly to the cornea as solutions or gels, as well as intravitreal, or subconjunctival injections. The common theme throughout all these projects is that the unique structure of the nanoparticles make them extremely versatile platforms for innovative scientists to adapt to overcome very different barriers. As our understanding of the pharmacokinetics of the eye increase, the ways for dendrimers and dendrimer based materials to improve drug delivery to this singularly complex organ will inevitably increase as well.

\section{Acknowledgments}

This work was supported by the National Institutes of Health (R01EY024072).

\section{References}

1. Quigley HA, Broman AT. Br. J. Ophthalmol. 2006; 90(3):262. [PubMed: 16488940]

2. Aref AA. Curr. Opin. Ophthalmol. 2017; 28(2):169-174. [PubMed: 27764023]

3. Rein DB. Invest. Ophthalmol. Vis. Sci. 2013; 54(14):ORSF18-22. [PubMed: 24335062] 
4. Vellonen KS, Soini EM, del Amo EM, Urtti A. Mol. Pharm. 2016; 13(9):2906-2911. [PubMed: 26674753]

5. Korte JM, Kaila T, Saari MK. Graefe's Arch. Clin. Exp. Ophthalmol. 2002; 240(6):430. [PubMed: 12107508]

6. Urtti A. Adv. Drug Delivery Rev. 2006; 58(11):1131.

7. Diebold Y, Calonge M. Prog. Retinal Eye Res. 2010; 29(6):596.

8. Zimmer A, Kreuter J. Adv. Drug Delivery Rev. 1995; 16(1):61.

9. Patel A, Cholkar K, Agrahari V, Mitra AK. World J. Pharm. 2013; 2(2):47.

10. Jóhannesson G, Stefánsson E, Loftsson T. Dev. Ophthalmol. 2016; 55:93-103. [PubMed: 26501994]

11. Bravo-Osuna I, Andrés-Guerrero V, Pastoriza Abal P, Molina-Martínez IT, Herrero-Vanrell R. Drug Deliv. Transl. Res. 2016; 6(6):686-707. [PubMed: 27766598]

12. Ban J, Zhang Y, Huang X, Deng G, Hou D, Chen Y, Lu Z. Int. J. Nanomedicine. 2017; 12:1329_ 1339. [PubMed: 28243093]

13. Di Colo G, Zambito Y. Eur. J. Pharm. Biopharm. 2002; 54(2):193. [PubMed: 12191691]

14. Yellepeddi VK, Palakurthi S. J. Ocular Pharm. Therapeutics. 2015

15. Coursey TG, Henriksson JT, Marcano DC, Shin CS, Isenhart LC, Ahmed F, De Paiva CS, Plugfelder SC, Acharya G. J. Control Rel. 2015; 213:168-74.

16. Da Silva GR, Lima TH, Oréfice RL, Fernandes-Cunha GM, Silva-Cunha A, Zhao M, Behar-Cohen F. Eur. J. Pharm. Sci. 2015; 73:9. [PubMed: 25797289]

17. Joseph RR, Venkatraman SS. Nanomedicine (Lond.). 2017; 12(6):683-702. [PubMed: 28186436]

18. Kambhampati SP, Kannan RM. J. Ocular Pharm. Therapeutics. 2013; 29(2):151.

19. Spataro G, Malecaze F, Turrin CO, Soler V, Duhayon C, Elena PP, Majoral JP, Caminade AM. Eur. J. Med. Chem. 2010; 45(1):326. [PubMed: 19889480]

20. Kannan R, Nance E, Kannan S, Tomalia D. J. Internal Medicine. 2014; 276(6):579-617.

21. Tomalia D, Baker H, Dewald J, Hall M, Kallos G, Martin S, Roeck J, Ryder J, Smith P. Macromolecules. 1986; 19(9):2466-2468.

22. Sultana Y, Jain R, Aqil M, Ali A. Curr. Drug Deliv. 2006; 3(2):207. [PubMed: 16611007]

23. Davies NM. Clin. Exp. Pharm. Physiol. 2000; 27(7):558.

24. Joseph M, Trinh HM, Cholkar K, Pal D, Mitra AK. Expert Opin. Drug Deliv. 2016:1-15.

25. Duvvuri S, Majumdar S, Mitra AK. Expert Opin. Biol. Ther. 2003; 3(1):45. [PubMed: 12718730]

26. Sleath B, Blalock S, Covert D, Stone JL, Skinner AC, Muir K, Robin AL. Ophthalmol. 2011; 118(12):2398.

27. Sayner R, Carpenter DM, Blalock SJ, Robin AL, Muir KW, Hartnett ME, Giangiacomo AL, Tudor G, Sleath B. Clin. Therapeutics. 2015; 37(9):1975.

28. Shaya FT, Mullins CD, Wong W, Cho J. Am. J. Managed Care. 2002; 8(10; SUPP):S271.

29. Lee VHL, Robinson JR. J. Ocular Pharm. Therapeutics. 1986; 2(1):67.

30. Prausnitz MR, Noonan JS. J. Pharm. Sci. 1998; 87(12):1479. [PubMed: 10189253]

31. Kaur IP, Smitha R. Drug Dev. Ind. Pharm. 2002; 28(4):353. [PubMed: 12056529]

32. Almeida H, Amaral MH, Lobao P, Frigerio C, Sousa Lobo JM. Curr. Pharm. Des. 2015; 21(36): 5212-24. [PubMed: 26412360]

33. Ranta VP, Mannermaa E, Lummepuro K, Subrizi A, Laukkanen A, Antopolsky M, Murtomäki L, Hornof M, Urtti A. J. Control Rel. 2010; 148(1):42-8.

34. Willekens K, Reyns G, Diricx M, Vanhove M, Noppen B, Coudyzer W, Ni Y, Feyen JH, Stalmans P. Invest. Ophthalmol. Vis. Sci. 2017; 58(3):1434-1441. [PubMed: 28264098]

35. Castellarin A, Pieramici DJ. Ophthalmol. Clin. North Am. 2004; 17(4):583-90. vii. [PubMed: 15533752]

36. Yan H, Cui J, Wang Y, Yu Y. Ophthalmic Res. 2013; 49(2):81-9. [PubMed: 23257710]

37. Madaan K, Kumar S, Poonia N, Lather V, Pandita D. J. Pharm. Bioallied Sci. 2014; 6(3):139. [PubMed: 25035633] 
38. Albertazzi L, Serresi M, Albanese A, Beltram F. Mol. Pharm. 2010; 7(3):680. [PubMed: 20394437]

39. Menjoge AR, Kannan RM, Tomalia DA. Drug Disc. Today. 2010; 15(5):171.

40. Cheng Y, Xu Z, Ma M, Xu T. J. Pharm. Sci. 2008; 97(1):123. [PubMed: 17721949]

41. Caminade AM, Turrin CO, Majoral JP. New J. Chem. 2010; 34(8):1512.

42. Bravo-Osuna I, Vicario-de-la-Torre M, Andres-Guerrero V, Sanchez-Nieves J, Guzman-Navarro M, de la Mata FJ, Gomez R, de las Heras B, Argueso P, Ponchel G, Herrero-Vanrell R, MolinaMartinez IT. Mol. Pharm. 2016; 13(9):2966-2976. [PubMed: 27149661]

43. Heredero-Bermejo I, Copa-Patino JL, Soliveri J, Fuentes-Paniagua E, de la Mata FJ, Gomez R, Perez-Serrano J. Parasitol Res. 2015; 114(2):473-86. [PubMed: 25358240]

44. Wimmer N, Marano RJ, Kearns PS, Rakoczy EP, Toth I. Bioorganic Med. Chem. Letters. 2002; 12(18):2635.

45. Wang WY, Yao C, Shao YF, Mu HJ, Sun KX. J. Pharm. Biomed. Anal. 2011; 56(4):825. [PubMed: 21831555]

46. Sweet DM, Kolhatkar RB, Ray A, Swaan P, Ghandehari H. J. Control Rel. 2009; 138(1):78.

47. El-Sayed M, Ginski M, Rhodes C, Ghandehari H. J. Control Rel. 2002; 81(3):355-65.

48. Kitchens KM, Kolhatkar RB, Swaan PW, Eddington ND, Ghandehari H. Pharm. Res. 2006; 23(12):2818. [PubMed: 17094034]

49. Vandamme TF, Brobeck L. J. Control Rel. 2005; 102(1):23.

50. Yao WJ, Sun KX, Liu Y, Liang N, Mu HJ, Yao C, Liang RC, Wang AP. Biological Pharm. Bull. 2010; 33(8):1371.

51. Bravo-Osuna I, Woodward A, Argueso P, Martínez ITM, Gómez R, de la Mata FJ, Navarro MM, Noiray M, Ponchel G, Herrero-Vanrell R. Invest. Ophthalmol. Visual Sci. 2012; 53(14):1845.

52. Souza JG, Dias K, Silva SAM, de Rezende LCD, Rocha EM, Emery FS, Lopez RFV. J. Control Rel. 2015; 200:115.

53. Grimaudo MA, Tratta E, Pescina S, Padula C, Santi P, Nicoli S. Int. J. Pharm. 2017; 521(1-2):214221. [PubMed: 28232201]

54. Kaga S, Arslan M, Sanyal R, Sanyal A. Molecules. 2016; 21(4):497. [PubMed: 27092481]

55. Grinstaff MW. Biomaterials. 2007; 28(35):5205-14. [PubMed: 17889330]

56. Yang H, Tyagi P, Kadam RS, Holden CA, Kompella UB. ACS Nano. 2012; 6(9):7595. [PubMed: 22876910]

57. Wang J, He H, Cooper RC, Yang H. ACS. Appl. Mater. Interfaces. 2017

58. Holden CA, Tyagi P, Thakur A, Kadam R, Jadhav G, Kompella UB, Yang H. Nanomedicine: Nanotechnology, Biology Med. 2012; 8(5):776.

59. McLaughlin MD, Hwang JC. Ophthalmol. 2017

60. Yavuz B, Bozdag Pehlivan S, Sumer Bolu B, Nomak Sanyal R, Vural I, Unlu N. J. Pharm. Pharmacol. 2016; 68(8):1010-20. [PubMed: 27283886]

61. Lajavardi L, Bochot A, Camelo S, Goldenberg B, Naud MC, Behar-Cohen F, Fattal E, de Kozak Y. Invest. Ophthalmol. Visual Sci. 2007; 48(7):3230. [PubMed: 17591893]

62. Iezzi R, Guru BR, Glybina IV, Mishra MK, Kennedy A, Kannan RM. Biomaterials. 2012; 33(3): 979. [PubMed: 22048009]

63. Kambhampati SP, Mishra MK, Mastorakos P, Oh Y, Lutty GA, Kannan RM. Eur. J. Pharm. and Biopharm. 2015; 95:239-249. [PubMed: 25701805]

64. Sakurai E, Ozeki H, Kunou N, Ogura Y. Ophthalmic. Res. 2000; 33(1):31.

65. Kim H, Robinson SB, Csaky KG. Pharm. Res. 2009; 26(2):329. [PubMed: 18958405]

66. Xu Q, Nicholas B, Suk JS, Wang YY, Nance E, Yang JC, McDonnell PJ, Cone RA, J E, Duh, Hanes J. J. Control Rel. 2013; 167(1):76-84.

67. Mehra NK, Cai D, Kuo L, Hein T, Palakurthi S. Nanotoxicology. 2016; 10(7):836-60. [PubMed: 27027670]

68. Ayalasomayajula SP, Kompella UB. Pharm. Res. 2004; 21(10):1797. [PubMed: 15553225]

69. Soiberman U, Kambhampati S, Wu T, Mishra M, Oh Y, Sharma R, Wang J, Al Towerki A, Yiu S, Stark W, Kannan R. Biomaterials. 2017; 125:38-53. [PubMed: 28226245] 
70. Kompella UB, Bandi N, Ayalasomayajula SP. Invest. Ophthalmol. Visual Sci. 2003; 44(3):1192. [PubMed: 12601049]

71. Kang SJ, Durairaj C, Kompella UB, O’Brien JM, Grossniklaus HE. Arch. Ophthalmol. 2017; 127(8):1043-1047.

72. Loftsson T, Sigurdsson HH, Hreinsdóttir D, Konradsdottir F, Stefansson E. J. Inclusion Phenom. Macrocyclic Chem. 2007; 57(1-4):585.

73. Rodríguez Villanueva J, Rodríguez Villanueva L, Guzmán Navarro M. Int. J. Pharm. 2017; 516(12):342-351. [PubMed: 27889587]

74. Yavuz B, Pehlivan SB, Vural I, Unlu N. J. Pharm. Sci. 2015; 104(11):3814-23. [PubMed: 26227825]

75. Nassiri Koopaei N, Abdollahi M. Daru. 2016; 24(1):23. [PubMed: 27716350]

76. Dobrovolskaia MA. J. Control Rel. 2015; 220(Pt B):571-83.

77. Amrite AC, Edelhauser HF, Singh SR, Kompella UB. Mol. Vis. 2008; 14:150-60. [PubMed: 18334929]

78. Korsmeyer R. Regen. Biomater. 2016; 3(2):143-7. [PubMed: 27047683]

79. Kleinbeck K, Anderson E, Ogle M, Burmania J, Kao WJ. Biointerphases. 2012; 7(1-4):12. [PubMed: 22589055]

80. Yao W, Sun K, Mu H, Liang N, Liu Y, Yao C, Liang R, Wang A. Drug Dev. Ind. Pharm. 2010; 36(9):1027. [PubMed: 20545508]

81. Richichi B, Baldoneschi V, Burgalassi S, Fragai M, Vullo D, Akdemir A, Dragoni E, Louka A, Mamusa M, Monti D. Chem. Eur. J. 2016; 22(5):1714. [PubMed: 26692423]

82. Mishra V, Jain NK. Int. J. Pharm. 2014; 461(1-2):380-90. [PubMed: 24291772]

83. Zhao L, Chen G, Li J, Fu Y, Mavlyutov TA, Yao A, Nickells RW, Gong S, Guo LW. J. Control Rel. 2017; 247:153-166. 


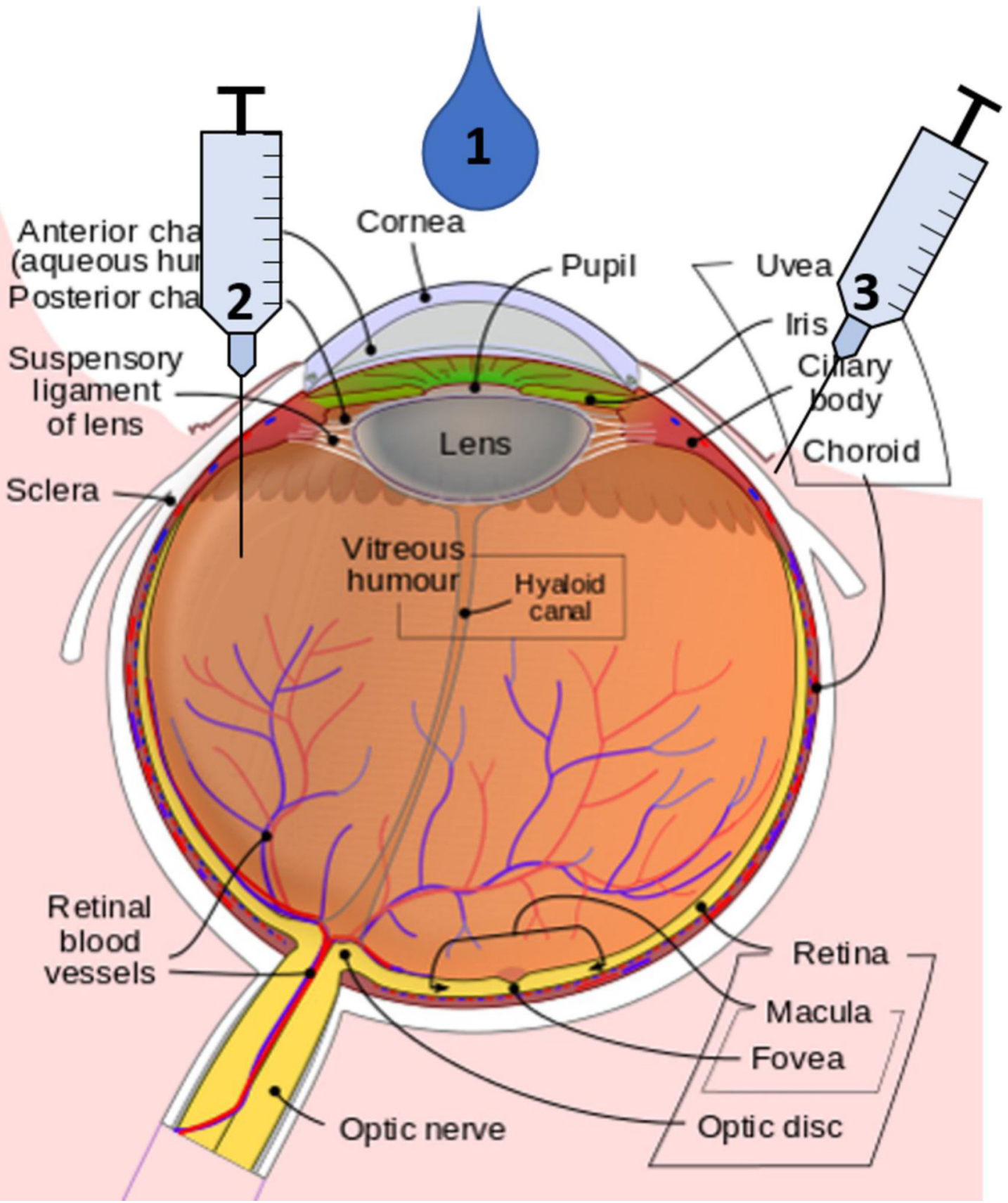

Figure 1.

Dendrimer routes of ocular administration. Dendrimer based vehicles have shown preclinical efficacy in delivering ocular drugs through multiple routes of administration. These include 1) topical application, 2) injection into the vitreous humor, and 3) injection into the tissues around the eye. The eye structure was adapted with permission from the copyright holder of this work from https://en.wikipedia.org/wiki/Eye, retrieved March 1, 2017. 


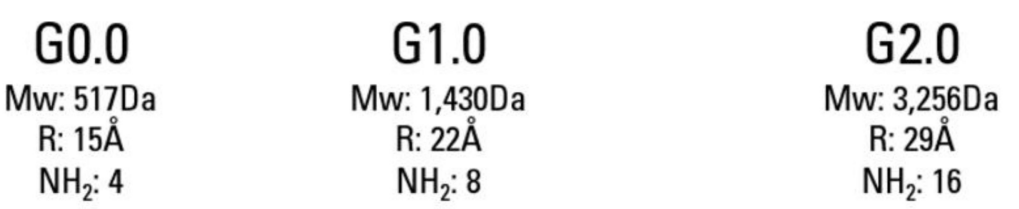

G3.0

Mw: 6,909Da

R: $36 \AA$

$\mathrm{NH}_{2}: 32$

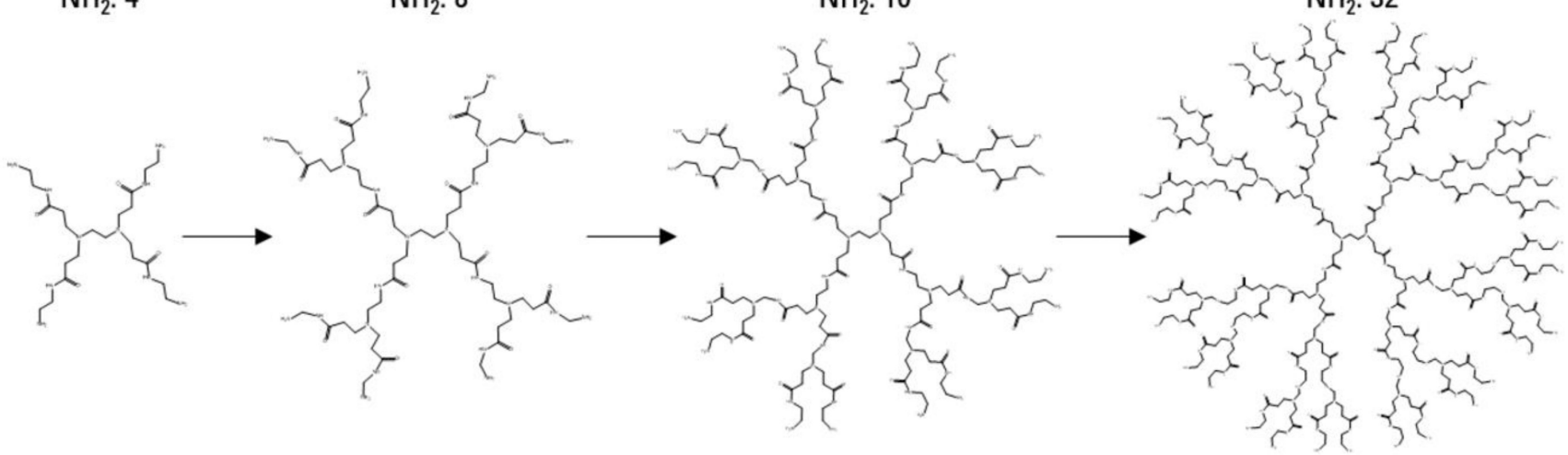

Figure 2.

Dendrimer synthesis and structure. PAMAM generations 0.0-3.0, with half generations omitted. Particle size grows linearly with each full generation, but molecular weight and the number of surface groups increase exponentially. 


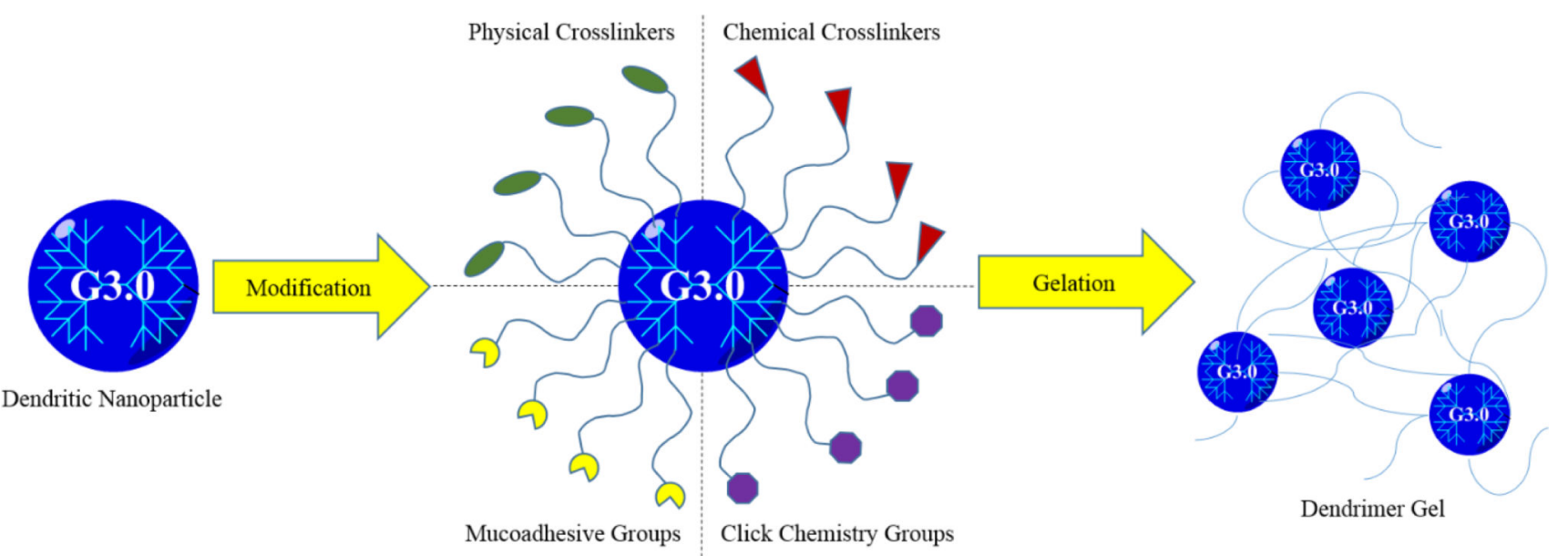

Figure 3.

Dendrimer gelation strategies. Dendrimers can be modified with diverse array of reactive groups to form hydrogels. Drug release from these materials can be further controlled by dendrimer type and generation, spacer length, and the mechanism of drug loading. 


\section{Table 1}

Preclinical ocular drug delivery studies utilizing dendrimer vehicles.

\begin{tabular}{lll}
\hline Dendrimer & Drug & Reference \\
\hline Topical Application & & \\
\hline PAMAM (G1.5-4.0) & Pilocarpine \& Tropicarmide & Vandamme et al. ${ }^{49}$ \\
PAMAM (G3.5-5.0) & Puerarin & Yao et al. ${ }^{80}$ \\
Carbosilane (G1.0-3.0) & Acetazolamide & Bravo-Osuna et al. ${ }^{42}$ \\
PAMAM (divalent) & Sulfonamide & Richichi et al. ${ }^{81}$ \\
PPI & Acetazolamide & Mishra et al. ${ }^{82}$ \\
PAMAM (G3.0 gel) & Timolol \& Brimonidine & Holden et al. ${ }^{58}$ \\
\hline Intravitreal Injection & & \\
\hline PAMAM (G4.0-OH) & Fluocinolone Acetonide & Iezzi et al. ${ }^{62}$ \\
PAMAM core micelle & S1R agonist & Zhao et al. ${ }^{83}$ \\
PAMAM (G4.0-OH) & Triamcinolone Acetonide & Kambhampati et al. ${ }^{63}$ \\
\hline Subconjunctival Injection & & \\
\hline PAMAM (G3.5) & Carboplatin & Kang et al. ${ }^{71}$ \\
PAMAM (G3.5, 4.5) & Dexamethasone & $\begin{array}{l}\text { Yavuz et al. }{ }^{60} \\
\text { PAMAM (G4.0-OH) }\end{array}$ \\
\hline
\end{tabular}

Can J Chem. Author manuscript; available in PMC 2018 September 01. 